\title{
Polymer multilevel lab-on-chip systems for electrochemical sensing
}

Matteucci, Marco; Larsen, Simon Tylsgaard; Garau, Alessandro; Tanzi, Simone; Taboryski, Rafael J.

Published in:

Journal of Vacuum Science and Technology. Part B. Microelectronics and Nanometer Structures

Link to article, DOI:

$10.1116 / 1.4832415$

Publication date:

2013

Document Version

Publisher's PDF, also known as Version of record

Link back to DTU Orbit

Citation (APA):

Matteucci, M., Larsen, S. T., Garau, A., Tanzi, S., \& Taboryski, R. J. (2013). Polymer multilevel lab-on-chip systems for electrochemical sensing. Journal of Vacuum Science and Technology. Part B. Microelectronics and Nanometer Structures, 31, 06F904-1. https://doi.org/10.1116/1.4832415

\section{General rights}

Copyright and moral rights for the publications made accessible in the public portal are retained by the authors and/or other copyright owners and it is a condition of accessing publications that users recognise and abide by the legal requirements associated with these rights.

- Users may download and print one copy of any publication from the public portal for the purpose of private study or research.

- You may not further distribute the material or use it for any profit-making activity or commercial gain

- You may freely distribute the URL identifying the publication in the public portal 


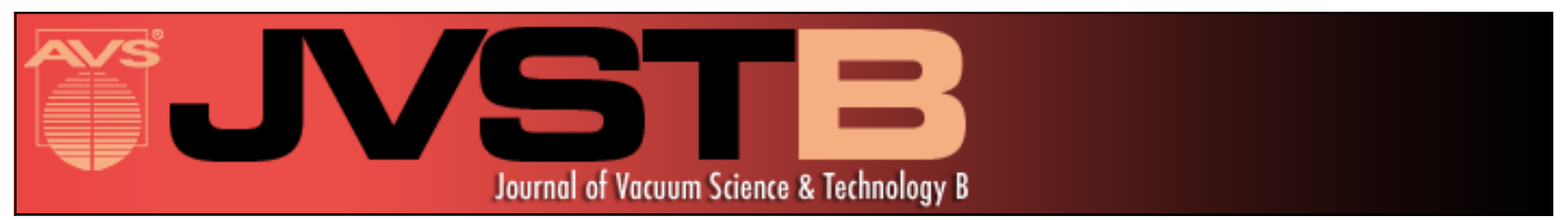

\section{Polymer multilevel lab-on-chip systems for electrochemical sensing}

Marco Matteucci, Simon Tylsgaard Larsen, Alessandro Garau, Simone Tanzi, and Rafael Taboryski

Citation: Journal of Vacuum Science \& Technology B 31, 06F904 (2013); doi: 10.1116/1.4832415

View online: http://dx.doi.org/10.1116/1.4832415

View Table of Contents: http://scitation.aip.org/content/avs/journal/jvstb/31/6?ver=pdfcov

Published by the AVS: Science \& Technology of Materials, Interfaces, and Processing

\section{Instruments for advanced science}
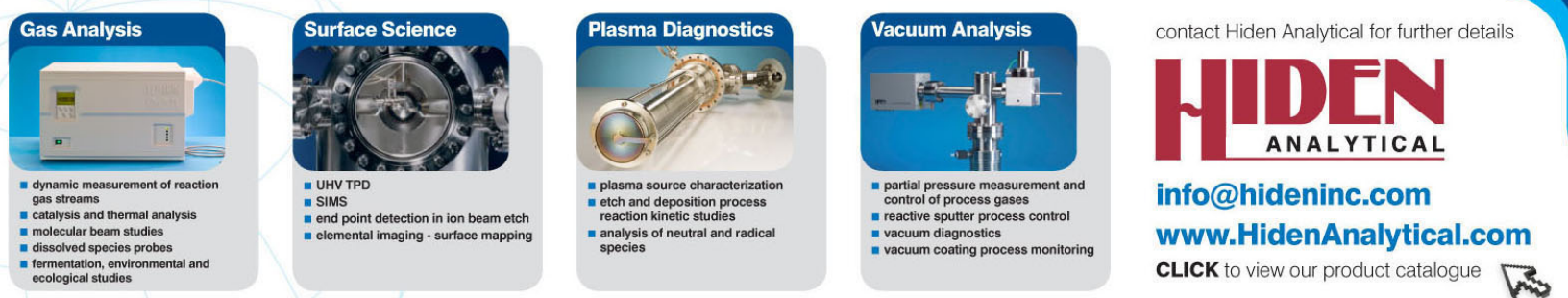


\title{
Polymer multilevel lab-on-chip systems for electrochemical sensing
}

\author{
Marco Matteucci, ${ }^{\text {a) }}$ Simon Tylsgaard Larsen, Alessandro Garau, Simone Tanzi, and \\ Rafael Taboryski \\ Department of Micro- and Nanotechnology, Technical University of Denmark, DTU Nanotech, Building 345E, \\ DK-2800 Kgs. Lyngby, Denmark
}

(Received 22 June 2013; accepted 7 November 2013; published 22 November 2013)

\begin{abstract}
The authors present a scheme intended for production of large quantities of lab on chip systems by means of Si dry etching, electroplating, injection molding, and pressure-assisted thermal bonding. This scheme allows for the fabrication of large numbers of samples having a combination of structures with depths as small as tens of nanometers and as big as hundreds of microns on the same polymer chip. The authors also describe in detail the fabrication procedure of polymer substrates with embedded $\mathrm{Au}$ and pedot:tosylate electrodes for electrochemical applications. The electrode fabrication process is simple and fit for integration in a production scheme. The electrode-substrates are then bonded to injection molded counterparts to be used for electrochemical applications. A dimensional and functional characterization of the electrodes is also presented here. (C) 2013 American Vacuum Society. [http://dx.doi.org/10.1116/1.4832415]
\end{abstract}

\section{INTRODUCTION}

In recent years, polymers have drawn more and more interest as materials for large scale fabrication of microfluidic and lab-on-chip (LoC) devices over the traditional approaches such as silicon and glass. ${ }^{1,2}$ Although many polymer fabrication methods are quite mature and are often used for prototyping, some drawbacks are present when it comes to industrial production and cost efficiency. ${ }^{3,4}$ At present, the most costeffective technologies for the large scale fabrication of micro and nanopatterned chips are the ones involving the molding of thermoplastic polymers such as injection molding and nanoimprinting. ${ }^{5}$

Here we present a production scheme (Fig. 1) for allpolymer devices made by means of dry etching, electroplating, injection molding, and thermal bonding. Such a scheme, suitable for large scale manufacturing was conceived to remove the technology barrier between lab-scale proof-of-principle and high-volume low-cost production of LoCs and to further enable new research by easy access to LoC technology. For this purpose, a design of a master (here referred to as shim) is discussed with the end-user in order to agree on required specifications of the final device. The following step is the fabrication of the shim: this is performed with a process that includes, among others, silicon dry etching and electroplating. ${ }^{6,7}$ The process allows the coupling of structures with dimensions (depths and widths) as small as $50 \mathrm{~nm}$ or less to structures having dimensions of few hundreds of microns. This is possible by overlapping standard reactive ion etching (RIE) and modified $\mathrm{BOSCH}$ processes during the shim fabrication thus obtaining multilevel shims. The shims are used to fabricate polymer chips on which standard luer connectors are coupled to micro and nanofluidic networks to ensure optimal interfacing with standard laboratory equipment. Although many thermoplastic polymers such as polystyrene, poly(methyl methacrylate) (PMMA), or polyethylene are suited for injection molding applications,

${ }^{a)}$ Electronic mail: mamat@nanotech.dtu.dk we chose the cyclic olefin copolymer TOPAS ${ }^{\mathrm{TM}} 5013 \mathrm{~L}$ for its high glass transition temperature (which allows thermal treatment of biological samples on-chip) and for its resistance to many solvents. ${ }^{8}$ The chips are finally thermally bonded with TOPAS lids of same grade. ${ }^{7}$ The lid thickness can vary from $50 \mu \mathrm{m}$ to $2 \mathrm{~mm}$ according to the requirements in substrate stiffness and detection optics (in case microscopy with lower depth of field is required). At present, batches of seven chips can be bonded at the same time with a throughput of $20 \mathrm{chips} / \mathrm{h}$. The polymer lids have been patterned to include either electrodes (Au or conductive polymer) or waveguides used for electrochemical or optofluidic purposes, respectively. Such fabrication and characterization methods ${ }^{9,10}$ are used to study topics such as single and multiple cell electrochemistry, ${ }^{11-14}$ DNA mapping, ${ }^{15-18}$ metaphase chromosomes, ${ }^{19}$ and electroporation. ${ }^{20}$ In Fig. 1, details of some of the chips used for these applications are shown.

Within the numerous LoCs, electrochemistry is playing an increasingly strong role both in boosting the development of LoC technology and in the growing number of applications. This is due to the fact that detection of currents that can be as low as a few pA has recently gained more and more interest: the requirements of ever decreasing detection limits in electrochemical sensing brought new technological challenges. ${ }^{21,22}$ For this purpose, micro- and nanofabricated electrodes can be made to be used not only for basic research ${ }^{23}$ but also for applications, among others, in the fields of health, ${ }^{24,25}$ food conservation, ${ }^{26}$ drug detection, ${ }^{27}$ and environmental monitoring. ${ }^{28,29}$ The advantages of reducing electrode dimensions are manifold: from the increased portability of monitoring devices to the higher performance in terms of signal-to-noise ratio to higher spatial and temporal resolution. Different materials have been studied both to increase sensing performance and to realize fabrication schemes suitable for large scale replica: not only electrodes are made from patterning of metals such as platinum and gold but also, among others, conducting polymers, ${ }^{12-14}$ pyrolized photoresist, ${ }^{30}$ nanowires ( $\mathrm{Si}$ and $\mathrm{Au}$ ) and nanoparticles, ${ }^{31}$ graphene and carbon nanotubes. ${ }^{32}$ Recently, a detection limit of $10^{-7} \mathrm{ng} / \mathrm{mL}$ 


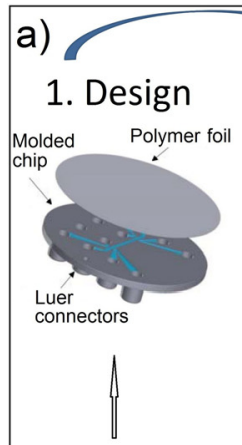

\section{Design} optimization (if needed)

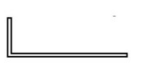

\section{Shim fabrication}

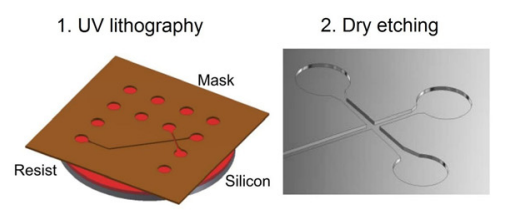

3. Nickel electroplating

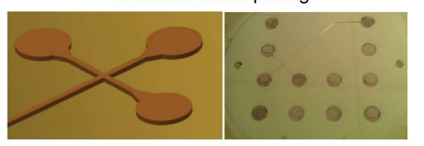

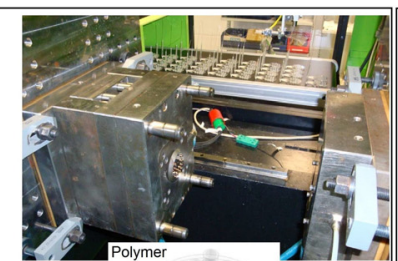

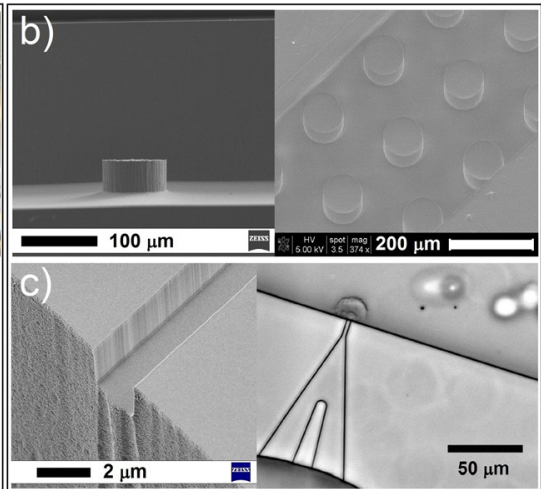

3. Injection molding \& bonding

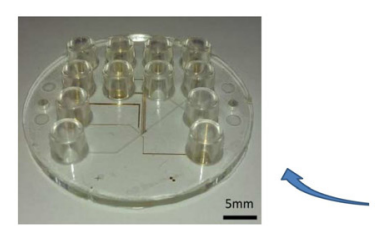

5. Delivery to end-user

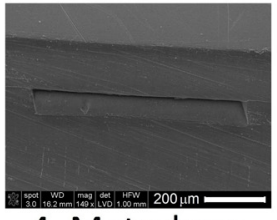

4. Metrology
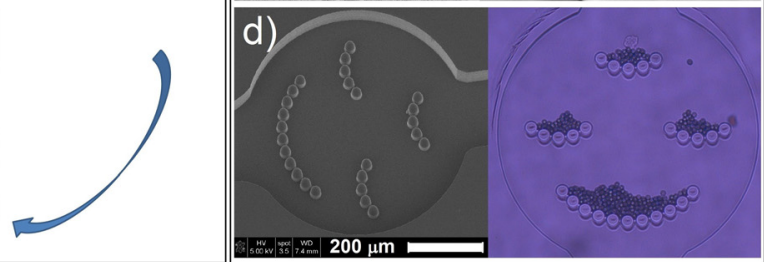

FIG. 1. (Color online) Scheme for fabrication of all-polymer LoCs. (a) After optimization of the design according to the end-user requirements, the shim is fabricated by overlapping a series of dry etching steps used to make shims that have channels and structures with sizes that can differ by more than three orders of magnitude $(50 \mathrm{~nm}-100 \mu \mathrm{m})$. The shims are then used to injection mold large number of samples that are then thermally bonded and characterized. After the delivery to the end user, in case further optimization is needed, design variations can be performed. Examples of applications: section of a Si channel of $250 \mu \mathrm{m}$ depth with embedded pillars and polymer chip for optofluidic detection (b) silicon master and final polymer chips for patch clamping of single HeLa cells (c). Silicon master for the fabrication of polymer chips for multiple cell capture and final chip showing the successful capture of beads of $10 \mu \mathrm{m}$ diameter (d).

for carcinoembryonic antigen was obtained with electrodes made by graphene loaded with gold nanoparticles. ${ }^{33}$

To integrate electrodes in polymer microfluidic chips, the use of pressure assisted thermal bonding of injection molded chips to substrates with pedot electrodes was previously demonstrated. ${ }^{20}$ One of the challenges of this technique is to ensure that optimal bonding using the required forces and temperatures does not cause deterioration of the electrodes in the areas where the electrodes enter the channel. This may cause increases in electrode resistance or, in the worst case, electrode disconnection. One of the solutions to this problem is to embed the electrodes in the substrate so to avoid electrode damage.

We here present a simple method for fabrication of both metal $(\mathrm{Au})$ and conductive polymer microelectrodes embedded in polymer substrates. The polymer substrates are then subsequently aligned and thermally bonded to injection molded microfluidic chips for LoC applications, thus making the whole process attractive for large scale production. The electrodes are finally characterized through electrochemical detection of ferrocene methanol with different concentrations.

\section{MATERIALS AND METHODS}

\section{A. Electrode fabrication}

The fabrication procedure for both $\mathrm{Au}$ and pedot:tosylate electrodes is shown in Fig. 2.

A TOPAS 5013L (TOPAS Advanced Polymers GmbH) substrate of $2 \mathrm{~mm}$ thickness and with nanometer roughness was injection molded by means of a commercial injection molding machine (ENGEL Victory 80/45). A $1.5 \mu \mathrm{m}$ thick layer of optical resist AZ1514E (Clariant) was then deposited on the TOPAS by means of spin coating (Opticoat SB20+, SSE Sister Semiconductor). To obtain negatively a)

Lithography

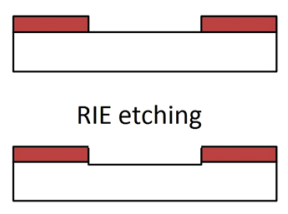

$\mathrm{Ti} / \mathrm{Au}$ deposition
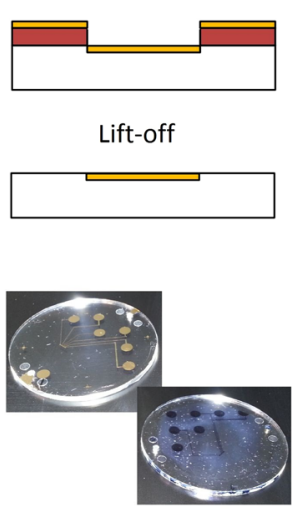

b)

Lithography

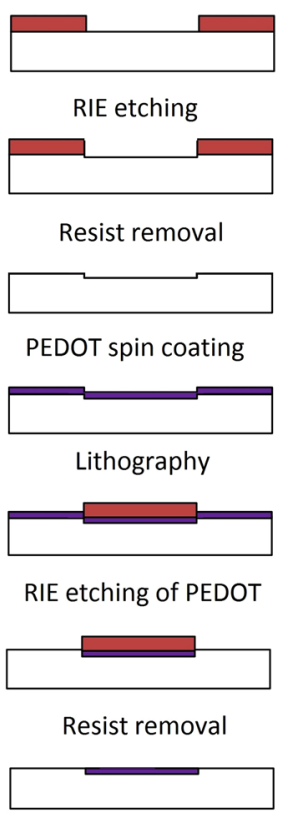

FIG. 2. (Color online) Fabrication scheme of Au (a) and pedot:tosylate (b) microelectrodes. Although the resist patterning steps are common for the two processes, when making the Au electrodes the resist is exposure is performed with a bright field mask (negative resist) while the patterning of the grooves for the pedot:tosylate electrodes is performed with dark field mask (positive resist). For Au electrodes, the RIE is followed by the deposition of the Ti/Au double layer and by the removal of the resist in acetone. The fabrication of pedot:tosylate electrodes is performed by spin coating a thin film of polymer on the etched substrate after resist removal. The spin coating is followed by an aligned lithography that has the purpose of defining the electrode pattern over the grooves. The excess pedot:tosylate is then removed by RIE whilst the excess resist is removed in acetone. 
sloped sidewalls and perform the liftoff, the AZ resist was treated as negative resist. For this reason, UV exposure was performed with a bright field mask for $4 \mathrm{~s}$ at an emitted power of $7 \mathrm{~mA} / \mathrm{cm}^{2}$ (Mask Aligner MA6, SUSS). The lithography was followed by a postexposure bake in oven at $120^{\circ} \mathrm{C}$ for $25 \mathrm{~min}$ and by a flood exposure that allowed tone reversal. Resist development was performed for $1 \mathrm{~min}$ in developer 1:5. The use of diluted developer allows longer development times and less aggressive removal of the resist, thus minimizing the risk of over-development of the sample. RIE in Cluster System C010 by Surface Technology Systems was performed to produce an $\mathrm{O}_{2} / \mathrm{CF}_{4}$ plasma $(95 / 5 \mathrm{sccm}$, $50 \mathrm{~W}$ RF power, $300 \mathrm{mTorr}$ chamber pressure, $70 \mathrm{~V}$ bias, and 3 min process time) and form the grooves in the TOPAS that would host the electrodes. The RIE process was tuned so to obtain grooves of about $300 \mathrm{~nm}$ depth. The reason for the choice of such depth is both to allow the deposition of thick conductive films (around $200 \mathrm{~nm}$ ) and at the same time avoid large difference in height between the electrode and the substrate surface. The latter is to avoid the flow of fluids from the microchannel into the groove hosting the electrode that could alter the measurements and, on the long run, ruin the electrode. Although the RIE process could influence the slope of the AZ resist and thus the liftoff efficiency, no significant changes were registered respect to a process that did not have the RIE step. After RIE, the deposition of a $10 \mathrm{~nm}$ $\mathrm{Cr}$ or $\mathrm{Ti}$ adhesion layer was followed by the deposition of the $200 \mathrm{~nm}$ Au electrode layer (SCM 600, Alcatel). The final electrodes were obtained by lifting off the resist in an acetone bath.

A different process was used to indent the TOPAS for the fabrication of the pedot:tosylate electrodes. Since AZ1514E can be treated both as positive and negative, a positive process was used to pattern the TOPAS substrate. For this reason, the spin coating of a $1.5 \mu \mathrm{m}$ thick layer of AZ resist was followed by a UV exposure with a dark field mask. The resist was exposed for $5.3 \mathrm{~s}$ with a lamp power of $7 \mathrm{~mW} / \mathrm{cm}^{2}$ to open the electrode patterns. The samples were then developed in standard AZ developer 1:5 for $1 \mathrm{~min}$. The RIE step was used to indent the TOPAS in the same way it was done for the fabrication of the Au electrodes. After removal of the $\mathrm{AZ}$ resist in acetone, a layer of pedot:tosylate of about $200 \mathrm{~nm}$ thickness was deposited on the substrate. This was done by spin coating a solution of $6.5 \mathrm{~mL}$ Clevios $^{\mathrm{TM}} \mathrm{CB} 40$ V2 (H.C. Starck), $2 \mathrm{~mL}$ butanol, $150 \mu \mathrm{L}$ pyridine (Fluka), and $220 \mu \mathrm{L}$ Clevios ${ }^{\mathrm{TM}} \mathrm{M}$ V2 (H.C. Starck) onto the TOPAS substrates at $1000 \mathrm{rpm}$ for $30 \mathrm{~s}$. The substrates were then baked on a hot plate at $70{ }^{\circ} \mathrm{C}$ to remove the remaining solvent, washed in deionized water, and blow-dried. This process gives a pedot:tosylate layer of about $200 \mathrm{~nm} .{ }^{12}$ Spin coating of another layer of AZ resist of $1.5 \mu \mathrm{m}$ in thickness was followed by an aligned exposure and development (like the ones used to pattern the TOPAS) to define the pedot:tosylate film over the grooves. In order to assure the complete filling of the cavities, the features on the mask used for the lithography had dimensions that exceeded by $2 \mu \mathrm{m}$ the ones of the cavities. The pedot:tosylate layer was then etched with RIE in $\mathrm{O}_{2} / \mathrm{N}_{2}(80 / 20 \mathrm{sccm}, 100 \mathrm{~W} \mathrm{RF}$ power, $300 \mathrm{mTorr}$ chamber pressure, $350 \mathrm{~V}$ bias, and 1:15 process time) and the resist was removed in an acetone bath. Since the RIE of pedot:tosylate increased the roughness of the TOPAS substrate, both the substrate and the injection molded counterpart were treated in air plasma for $2 \mathrm{~min}$. Air plasma is performed by inserting the samples into a chamber where pressure is pumped down to 450 mTorr with a rotary pump and kept at this constant value through the whole treatment by the use of a hand valve. No measurement of the flow is performed during the plasma whilst the pressure was measured by standard controller. An RF power source was used to ignite the plasma with a power of $50 \mathrm{~W}$ for $30 \mathrm{~s}$.

Substrates with $\mathrm{Au}$ and pedot:tosylate electrodes were thermally bonded to injection molded counterparts of TOPAS 5013L (Fig. 3) that were made according to the fabrication procedure described in detail elsewhere. ${ }^{6}$ Such counterparts included microchannels and luer connectors and were bonded to the substrates by pressure-enhanced thermal bonding. The microchannels have widths of $400 \mu \mathrm{m}$ and heights of 50 and $85 \mu \mathrm{m}$, respectively, for two different device iterations. The samples were pressed for $5 \mathrm{~min}$ with a force of $5 \mathrm{kN}$ at a constant temperature of $120^{\circ} \mathrm{C}$. In order to enhance the bonding strength the surfaces in contact were also UV-treated for $30 \mathrm{~s}$ before bonding. Further details of the bonding process and its characterization can be found elsewhere. $^{7}$ Alignment between microchannels and

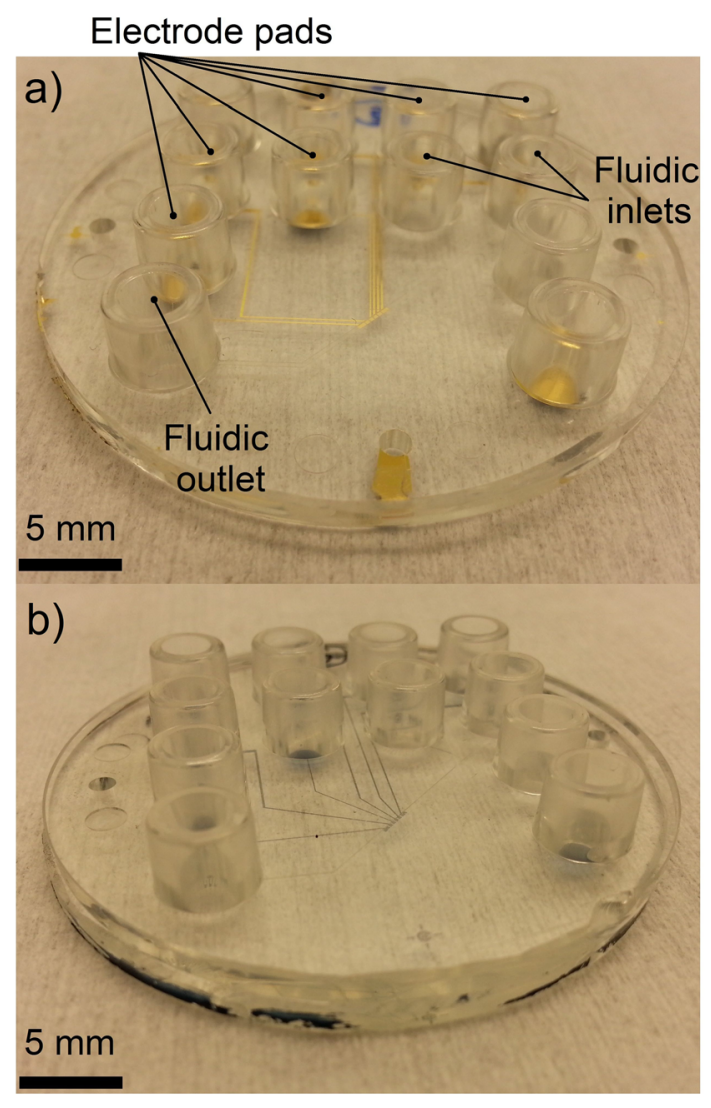

FIG. 3. (Color online) Bonded chips with Au (a) and pedot:tosylate (b) electrodes. The chips are formed by a top part ( $2 \mathrm{~mm}$ thick) in which the integrated luer connectors for both fluidics and electric connections are included together with the microfluidic circuit. The bottom substrate ( $2 \mathrm{~mm}$ thick) is the one on which the electrodes are patterned. 


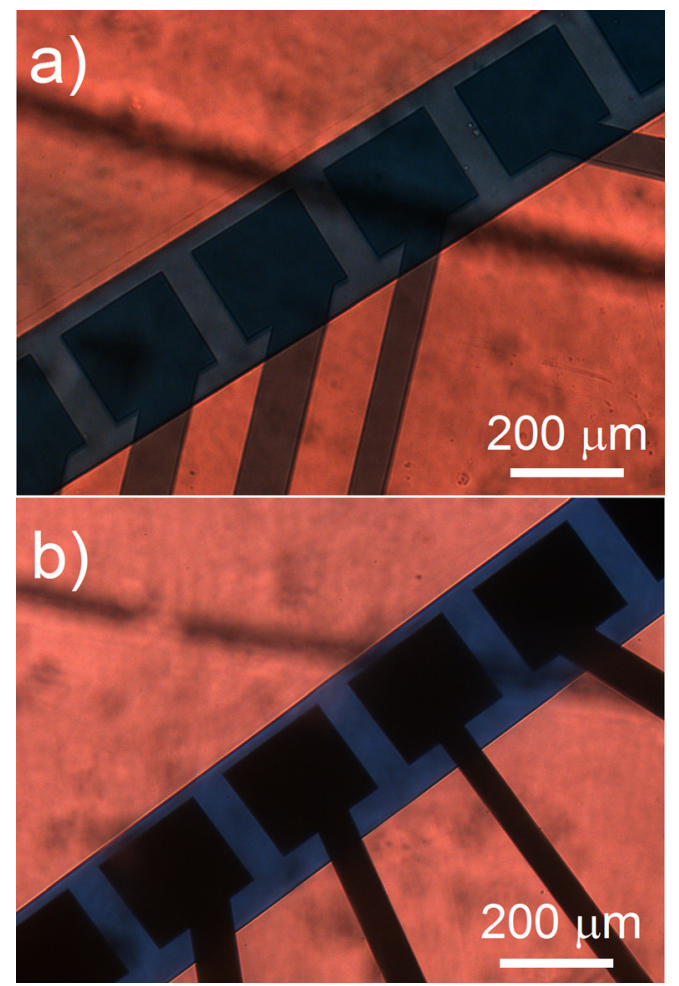

FIG. 4. (Color online) Pedot:tosylate (a) and Au (b) electrodes after bonding to microfluidic TOPAS chip. The channels were filled with blue dye to show the absence of leaks in the system.

electrodes was performed under an optical microscope before bonding. Fig. 4 shows details of both pedot:tosylate and $\mathrm{Au}$ electrodes after bonding to the microfluidic chip.

\section{B. Cyclic voltammetry}

To characterize the electrodes, a ferrocene methanol suspension (Sigma Aldrich) was diluted in phosphate buffer solution at concentrations ranging from $200 \mu \mathrm{M}$ to $1 \mathrm{mM}$. A 2-electrode configuration was used and the potentiostat (Dagan Chem Clamp, Dagan Corporation) was connected to the working electrode by a counter electrode made of an $\mathrm{Ag} / \mathrm{AgCl}$ (RE-5B, BASi). The counter electrode was placed in the luer used as outlet of the microfluidic chip after the filling of the channels with the ferrocene suspension. The working electrode was connected to the potentiostat by either using conductive epoxy glue or by pin connectors embedded in standard luer male connectors. The latter solution was found to be more user-friendly although it increases the chance of damaging the electrode pads on the TOPAS substrate. The electroactive area of the Au and pedot:tosylate films was defined by measurement of the area of the electrode that was included inside the channel. The electrode

TABLE I. Dimensions of the five different electrodes used. The latter include electrode areas (A), as well as electrode widths (w) and heights (h).

\begin{tabular}{lccccc}
\hline \hline & 1 & 2 & 3 & 4 & 5 \\
\hline $\mathrm{A}\left(\mu \mathrm{m}^{2} * 10^{4}\right)$ & 1.05 & 2.3 & 4.27 & 9 & 17.52 \\
$\mathrm{w} * \mathrm{~h}(\mu \mathrm{m} * \mu \mathrm{m})$ & $35 \times 300$ & $85 \times 270$ & $150 \times 285$ & $300 \times 300$ & $615 \times 285$ \\
\hline \hline
\end{tabular}

areas are shown in Table I. Electrochemical data were collected using custom programs written in LabVIEW software. These were used to apply a triangular voltage waveform with a fixed scan rate and to measure the resultant current.

\section{RESULTS AND DISCUSSION}

Measurements of the difference in height between the electrodes and the TOPAS substrates were performed with standard mechanical profilometry. In both cases ( $\mathrm{Au}$ and pedot:tosylate) the difference in height was between 50 and $100 \mathrm{~nm}$. This was enough to ensure the electrode integrity after bonding and at the same time avoid evident infiltration of fluid into the electrode casing from the fluidic channel.

By sweeping the current slowly $(2-10 \mathrm{mV} / \mathrm{s})$ from $-100 \mathrm{mV}$ to $500 \mathrm{mV}$, we obtained step-shaped slow-scan voltammograms, characteristic of microelectrodes [Fig. 5(a)]. At low potentials, little current is measured since the oxidation of ferrocene requires a sufficiently positive electrode potential. At potentials larger than the oxidation potential, the ferrocene molecules at the electrode are oxidized to

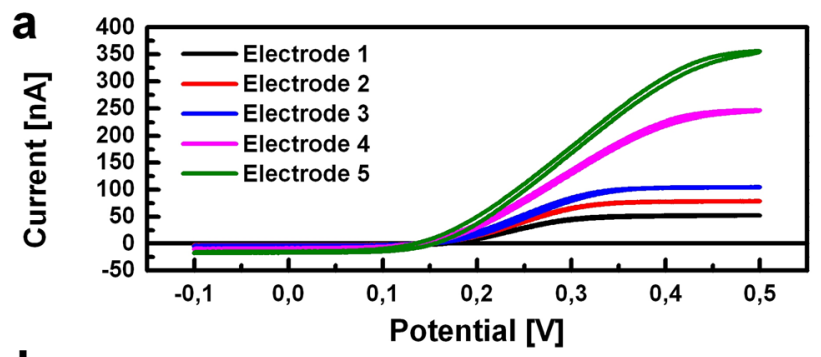

b
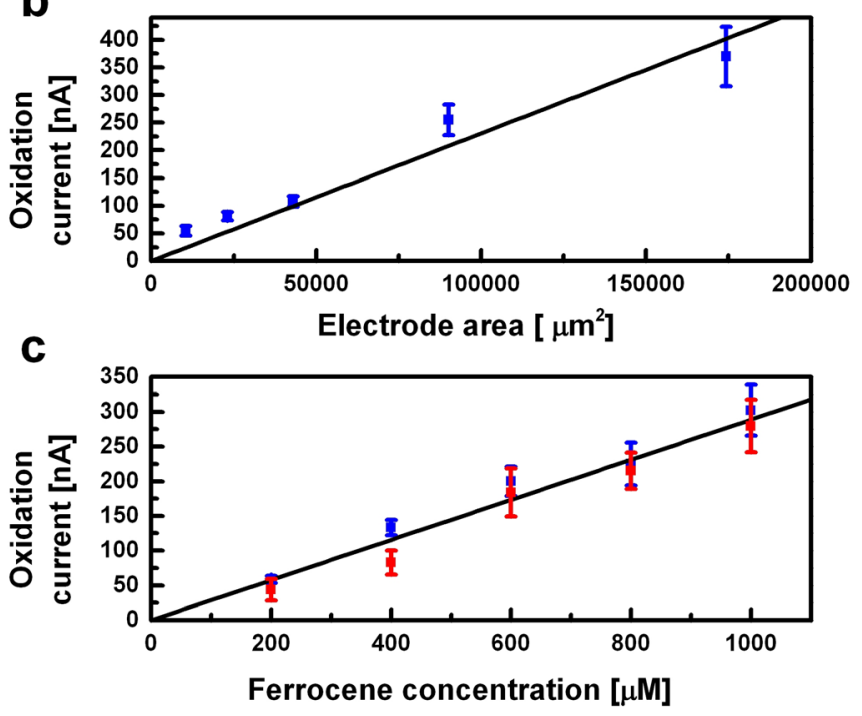

FIG. 5. (Color online) Electrochemical characterization of the integrated electrodes. (a) Cyclic voltammograms showing the oxidation of ferrocene methanol at integrated gold electrodes with varying area. Scan rate: $10 \mathrm{mV} / \mathrm{s}$. (b) Oxidation currents (measured as the step height of the voltammograms shown in (a) as a function of electrode area. The black line is a linear fit to the measured data. (c) Oxidation currents for different concentration of ferrocene methanol measured at a gold electrode (electrode 4) and a Pedot:tosylate electrode of same dimensions. The line is a linear fit to the measured data (both series, since the same behavior is expected at gold and Pedot:tosylate). Error bars in panels (b) and (c) are calculated from propagation of estimated uncertainties in electrode area $(5-15 \%)$, concentration $(5 \%)$, and from the error in the reading of plateau values. 
ferrocenium cations and the current depends on the diffusion of new molecules to the electrode. For microelectrodes, this current approaches a steady state (or quasisteady state), due to spherical diffusion to the electrode. ${ }^{34}$ The potential, where the current is half the steady state value, is termed the halfwave potential. We measured the half-wave potentials to be in the range of $230-300 \mathrm{mV}$, which is within the range normally measured for ferrocene methanol. The oxidation current (or steady state current for large potentials) seems to scale with electrode area for our integrated gold electrodes [Fig. 5(b)]. Compared to the linear regression, the response of the smaller electrodes seems higher than expected. This could be due to undesired flow in the microchannel. The fact that this divergence is not present for the larger electrodes is probably due to the fact that the current measurements on the latter were performed later, thus giving time for the flow to decrease significantly. We also varied the concentration of ferrocene methanol and measured oxidation currents at electrode 4 and at a Pedot:tosylate electrode with same dimensions [Fig. 5(c)]. As expected, the oxidation current scales linearly with the concentration of the electroactive compound. As expected, we observe similar oxidation currents for Pedot:tosylate and $\mathrm{Au}$, indicating that the response is only affected by the ferrocene concentration and the electrode/channel geometry and not by electrochemical properties at the electrode surface.

Since lower electrochemical detection limits can be obtained with smaller electrodes, embedded band electrodes as small as $8 \mu \mathrm{m}$ (Fig. 6) have also been fabricated and are being tested at present.

The microelectrodes presented can be integrated in LoC systems for various analytical applications. Apart from amperometric detection of neurotransmitter release from living cells, which has been presented in this paper, other potential applications could be separation techniques such as high performance liquid chromatography and capillary electrophoresis. These techniques can be coupled with electrochemical detection by placing an electrode at the end of the separation

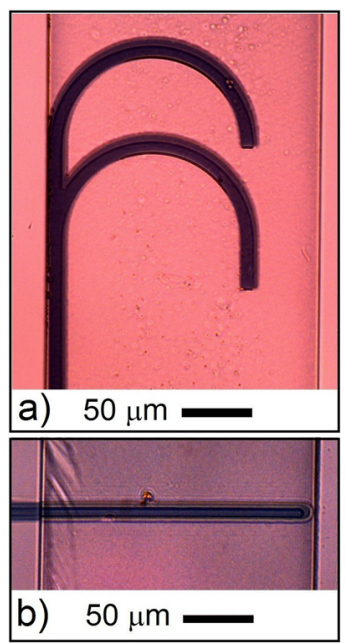

FIG. 6. (Color online) Curved (a) and linear (b) pedot:tosylate band electrodes. In both cases, the groove is $8 \mu \mathrm{m}$ wide while the width of the pedot:tosylate layer is $10 \mu \mathrm{m}$. column and they thus represent obvious applications for our electrochemical LoC systems. Also, due to their low noise and fast responses, microelectrodes can be used to detect single vesicle release events from neuronal cells at the millisecond scale. The applications mentioned here have all been realized successfully on silicon LoC systems but not on lowcost polymer systems.

\section{CONCLUSIONS}

We have described a scheme for fabrication of large number of LoCs that is intended as a first step toward LoC production. The core of this scheme is the fabrication of polymer chips by a combination of dry etching, electroplating, injection molding, and pressure enhanced thermal bonding. This scheme has allowed fabrication of polymer chips that are used, among others, for research purposes in the fields of cell electrochemistry, DNA mapping, metaphase chromosomes, and electroporation. Moreover, we successfully coupled both pedot:tosylate and gold electrodes embedded in polymer substrates, to injection molded polymer chips. The electrodes are made so to avoid electrode damage that could occur due to thermal bonding. The fabrication is performed by simple lithography and etching steps and thus can be readily integrated into a production scheme. The electrode characterization showed a linear dependence of oxidation current both to the concentration of the electroactive compound ferrocene methanol and the electrode area. Although further experiments need to be performed to assess the detection limit of electrodes made with this technique, the described results indicate that the latter potentially can be used in a wide range of LoC applications.

\section{ACKNOWLEDGMENTS}

This work was supported by the Danish Council for Strategic Research through the Strategic Research Center PolyNano (Grant No. 10-092322/DSF). The authors gratefully thank all the partners within the Polynano consortium for the continuous stimuli and the efforts toward the common goals. The authors would also like to acknowledge Letizia Amato (DTU-Nanotech) for the help received in the fabrication of nonembedded Au electrodes as well as Arto Heiskanen (DTU-Nanotech) for the useful discussions.

\footnotetext{
${ }^{1}$ A. de Mello, Lab Chip 2, 31N (2002).

${ }^{2}$ H. Andersson and A. van den Berg, Sens. Actuator B 92, 315 (2003).

${ }^{3}$ E. Sollier, C. Murray, P. Maoddi, and D. Di Carlo, Lab Chip 11, 3752 (2011).

${ }^{4}$ J. S. Kuo and D. T. Chiu, Lab Chip 11, 2656 (2011).

${ }^{5}$ U. M. Attia and J. R. Alcock, Int. J. Adv. Manuf. Tech. 48, 973 (2010).

${ }^{6} \mathrm{~S}$. Tanzi, P. F. Østergaard, M. Matteucci, T. L. Christiansen, J. Cech, R. Marie, and R. Taboryski, J. Micromech. Microeng. 22, 115008 (2012).

${ }^{7}$ M. Matteucci, T. L. Christiansen, S. Tanzi, P. F. Østergaard, S. T. Larsen, and R. Taboryski, Microelectron. Eng. 111, 294 (2013).

${ }^{8}$ TOPAS advanced polymers. See: http://www.topas.com

${ }^{9}$ M. Calaon, G. Tosello, H. N. Hansen, C. Ravn, and A. Islam, in Proceedings of ANTEC2012, Orlando, FL, 2-4 April (2012), pp. $1867-1872$.

${ }^{10}$ M. Calaon, H. N. Hansen, G. Tosello, J. Garnæs, C. Ravn, and P. T. Tang, in Proceedings of 12th International Conference of the European Society for Precision Engineering and Nanotechnology (euspen), 4-8 June, Stockholm, Sweden (2012), Vol. 1, pp. 288-291.
} 
${ }^{11} \mathrm{~S}$. T. Larsen, M. Matteucci, and R. J. Taboryski, in Proceedings of Nanotech Conference and Expo 2012 (2012), Vol. 2, pp. 302-305.

${ }^{12}$ S. T. Larsen, R. F. Vreeland, M. L. Heien, and R. J. Taboryski, Analyst 137, 1831 (2012).

${ }^{13}$ S. Tanzi, S. T. Larsen, M. Matteucci, and R. Taboryski, in Proceedings of the NSTI Nanotechnology Conference and Expo (2012), pp. 376-379.

${ }^{14}$ S. T. Larsen, M. L. Heien, and R. Taboryski, Anal. Chem. 84, 7744 (2012).

${ }^{15}$ R. Marie and A. Kristensen, J. Biophoton. 5, 673 (2012).

${ }^{16}$ R. L. Welch, R. Sladek, K. Dewar, and W. W. Reisner, Lab Chip 12, 3314 (2012).

${ }^{17}$ R. Marie, J. N. Pedersen, D. L. Bauer, K. H. Rasmussen, M. Yusuf, E. Volpi, H. Flyvbjerg, A. Kristensen, and K. U. Mir, Proc. Natl. Acad. Sci. U.S.A. 110, 4893 (2013).

${ }^{18}$ P. F. Østergaard, M. Matteucci, W. Reisner, and R. Taboryski, Analyst 138, 1249 (2013).

${ }^{19}$ D. L. Bauer, R. Marie, K. H. Rasmussen, A. Kristensen, and K. U. Mir, Nucleic Acids Res. 40, 11428 (2012).

${ }^{20} \mathrm{~K}$. Ø. Andresen et al., J. Micromech. Microeng. 20, 055010 (2010).

${ }^{21}$ Chang Ming Li and Weihua Hu, J. Electroanal. Chem. 688, 20 (2013).

${ }^{22}$ M. Ongaro and P. Ugo, Anal. Bioanal. Chem. 405, 3715 (2013).
${ }^{23}$ S. Bergner, P. Vatsyayan, and F.-M. Matysik, Anal. Chim. Acta 775, 1 (2013).

${ }^{24}$ M. Matteucci, R. Carabalona, M. Casella, E. Di Fabrizio, F. Gramatica, M. Di Rienzo, E. Snidero, L. Gavioli, and M. Sancrotti, Microelectron. Eng. 84, 1737 (2007).

${ }^{25}$ S. M. Cristescu, J. Mandon, F. J. M. Harren, P. Meriläinen, and M. Hogman, J. Breath Res. 7, 017104 (2013).

${ }^{26}$ T. Majumdar, R. Chakraborty, and U. Raychaudhuri, J. Electrochem. Soc. 160, G75 (2013).

${ }^{27}$ S. T. Larsen and R. Taboryski, Analyst 137, 5057 (2012).

${ }^{28}$ M. Yücel, P. E. Galand, S. K. Fagervold, L. Contreira-Pereira, and N. Le Bris, Chemosphere 90, 403 (2013).

${ }^{29}$ K. Vopel, P. S. Wilson, and J. Zeldis, Mar. Polluti. Bull. 64, 2885 (2012).

${ }^{30}$ S. T. Larsen, A. Argyraki, L. Amato, S. Tanzi, S. S. Keller, N. Rozlosnik, and R. J. Taboryski, ECS Electrochem. Lett. 2, B5 (2013).

${ }^{31}$ L. Zhang, D. Lv, W. Su, Y. Liu, Y. Chen, and R. Xiang, Am. J. Biochem. Biotechnol. 9, 71 (2013).

${ }^{32}$ E. K. Wujcik and C. N. Monty, WIREs Nanomed. Nanobiotechnol. 5, 233 (2013).

${ }^{33}$ N. Liu, X. Chen, and Z. Ma, Biosens. Bioelectron. 48, 33 (2013).

${ }^{34}$ A. J. Bard and L. R. Faulkner, Electrochemical Methods, 2nd ed. (John Wiley \& Sons Inc., New York, 2001). 